NASA/TM—2011-217254

\title{
An Overview of NASA Engine Ice-Crystal Icing Research
}

Harold E. Addy, Jr. and Joseph P. Veres

Glenn Research Center, Cleveland, Ohio 


\section{NASA STI Program . . . in Profile}

Since its founding, NASA has been dedicated to the advancement of aeronautics and space science. The NASA Scientific and Technical Information (STI) program plays a key part in helping NASA maintain this important role.

The NASA STI Program operates under the auspices of the Agency Chief Information Officer. It collects, organizes, provides for archiving, and disseminates NASA's STI. The NASA STI program provides access to the NASA Aeronautics and Space Database and its public interface, the NASA Technical Reports Server, thus providing one of the largest collections of aeronautical and space science STI in the world. Results are published in both non-NASA channels and by NASA in the NASA STI Report Series, which includes the following report types:

- TECHNICAL PUBLICATION. Reports of completed research or a major significant phase of research that present the results of NASA programs and include extensive data or theoretical analysis. Includes compilations of significant scientific and technical data and information deemed to be of continuing reference value. NASA counterpart of peer-reviewed formal professional papers but has less stringent limitations on manuscript length and extent of graphic presentations.

- TECHNICAL MEMORANDUM. Scientific and technical findings that are preliminary or of specialized interest, e.g., quick release reports, working papers, and bibliographies that contain minimal annotation. Does not contain extensive analysis.

- CONTRACTOR REPORT. Scientific and technical findings by NASA-sponsored contractors and grantees.
- CONFERENCE PUBLICATION. Collected papers from scientific and technical conferences, symposia, seminars, or other meetings sponsored or cosponsored by NASA.

- SPECIAL PUBLICATION. Scientific, technical, or historical information from NASA programs, projects, and missions, often concerned with subjects having substantial public interest.

- TECHNICAL TRANSLATION. Englishlanguage translations of foreign scientific and technical material pertinent to NASA's mission.

Specialized services also include creating custom thesauri, building customized databases, organizing and publishing research results.

For more information about the NASA STI program, see the following:

- Access the NASA STI program home page at http://www.sti.nasa.gov

- E-mail your question via the Internet to help@ sti.nasa.gov

- Fax your question to the NASA STI Help Desk at $443-757-5803$

- Telephone the NASA STI Help Desk at 443-757-5802

- Write to: NASA Center for AeroSpace Information (CASI) 7115 Standard Drive Hanover, MD 21076-1320 
NASA/TM—2011-217254

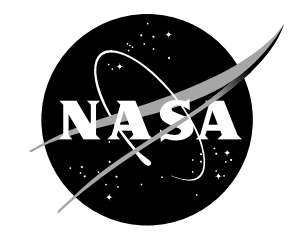

\section{An Overview of NASA Engine Ice-Crystal Icing Research}

Harold E. Addy, Jr. and Joseph P. Veres

Glenn Research Center, Cleveland, Ohio

Prepared for the

International Conference on Aircraft and Engine Icing and Ground Deicing

sponsored by the SAE International

Chicago, Illinois, June 13-17, 2011

National Aeronautics and

Space Administration

Glenn Research Center

Cleveland, Ohio 44135 
Trade names and trademarks are used in this report for identification only. Their usage does not constitute an official endorsement, either expressed or implied, by the National Aeronautics and Space Administration.

Level of Review: This material has been technically reviewed by technical management.

Available from

NASA Center for Aerospace Information 7115 Standard Drive

Hanover, MD 21076-1320
National Technical Information Service 5301 Shawnee Road Alexandria, VA 22312

Available electronically at http://www.sti.nasa.gov 


\title{
An Overview of NASA Engine Ice-Crystal Icing Research
}

\author{
Harold E. Addy, Jr. and Joseph P. Veres \\ National Aeronautics and Space Administration \\ Glenn Research Center \\ Cleveland, Ohio 44135
}

\begin{abstract}
Ice accretions that have formed inside gas turbine engines as a result of flight in clouds of high concentrations of ice crystals in the atmosphere have recently been identified as an aviation safety hazard. NASA's Aviation Safety Program (AvSP) has made plans to conduct research in this area to address the hazard. This paper gives an overview of NASA's engine ice-crystal icing research project plans. Included are the rationale, approach, and details of various aspects of NASA's research.
\end{abstract}

\section{Background}

What is NASA doing? The NASA Atmospheric Environment Safety Technologies (AEST) Project seeks, in collaboration with our partners and the aviation industry, to develop key technologies needed to address the problem of aircraft engine icing; in particular, ice-crystal icing. These key technologies include knowledge bases, analysis methods, and simulation tools-both computational and experimental.

For many years, the term engine icing has been used to describe ice accreting on exposed engine surfaces as an aircraft flies through a cloud of supercooled liquid droplets. The liquid droplets freeze on impact, or shortly thereafter, to form obstructions to, and create distortions in, air flowing into the engine. In the case of a jet-based engine, these exposed surfaces include those in the inlet, the spinner, the fan blades, and initial stages of the compressor. In these locations, ice accretions not only result in degraded engine performance, but also constitute a source of foreign object damage (FOD) to the engine in the event they suddenly are shed from the surface to which they are adhered and impact critical engine components. In the case of reciprocating, naturally aspirated, carburetor engines, ice can accrete in the throat of the carburetor, resulting in total power loss. While these problems continue to be a challenge for the aviation industry, methods have been, and continue to be, developed to address them.

However, engine icing due to the accretion of ice inside the normally hot core of jet-based engines due to flight in clouds of highly concentrated ice-crystals is a recently identified problem. It is a problem whose frequency is alarmingly high. Its counter-intuitive and complex nature has resulted in numerous calls for research into the phenomenon such that it may be more effectively addressed. Therefore, NASA AEST is investing its engine icing resources in high ice-water content (HIWC) icing research.

Why is NASA doing it? Evidence indicates that engine icing incidents caused by ice accreting inside the core of jet-based engines have been occurring for over two decades. However, the phenomenon is difficult to identify. Ice crystals normally bounce off exposed aircraft surfaces and do not accrete.

Temperatures inside an engine compressor quickly rise to well above freezing under normal flight conditions. Icing due to the freezing of supercooled liquid droplets cannot occur under these circumstances. Given these circumstances, the possibility of ice accreting inside and engine core seemed unlikely. Nevertheless, analyses of engine incidents including compressor surge and stall, combustor flameout, engine rollback, and engine damage during and after flight in HIWC indicated that this, indeed, was the cause. A concerted effort, including meteorologists and engine and airframe manufacturers, was required to determine and identify the causes of these engine events. Moreover, even though engine core icing was confirmed, the complex, aero-thermodynamics involved that permit ice to accrete inside the core of an engine in flight are not understood to a level that allows effective analysis and prevention or mitigation techniques to be employed in a robust manner. 
Studies of aircraft engine incidents have identified over 140 engine power loss events due to engine core icing since the early 1980's (Ref. 1). Both commuter and large transport airplanes were involved. Fourteen of these were multi-engine flameouts. On one of these, the pilots were unable to restart the engines. Fortunately, a dead-stick landing was successfully accomplished. Hazardous events such as these will continue to occur unless more robust means to address the problem are developed.

The immediacy of the engine core icing problem is illustrated by the degree of involvement by the aviation industry. The FAA has proposed new certification requirements for regularly-scheduled aircraft with jet engines that fly in HIWC conditions. These conditions are described in Reference 2 and were drawn up by the combined efforts of two Aviation Rulemaking Advisory Committee-commissioned groups, the Ice Protection Harmonization Working Group and the Engine Harmonization Working Group. On its own initiative, the Engine Harmonization Working Group subsequently drafted a MixedPhase/Glaciated Icing Technology Plan (Ref. 3). This plan details several key technology areas that need to be developed in order for the engine core icing hazard to be effectively addressed. In addition, a small group of engine and airframe manufacturers formed a consortium, the Ice Crystal Consortium (ICC), to pool resources to address the problem. ICC membership is limited to non-government companies. Research sponsored by the ICC is proprietary. The arrangement makes collaboration with NASA difficult, but discussions between NASA and the ICC are ongoing and are a benefit to both. The fact that these companies, many in direct competition in the marketplace, have banded together to address the problem is a strong indication of the urgency of the engine core icing problem.

Finally, several NASA investigations of aircraft safety incidents and accidents have documented the importance of research in the area of engine icing, in particular, engine core icing. These include the NASA Loss of Control Study Report (Ref. 4), Systems Analysis of NASA Aviation Safety Program-Final Report (Ref. 5), and Causal Factors and Adverse Conditions of Aviation Accidents and Incidents Related to Integrated Resilient Aircraft Control (Ref. 6).

\section{Current Practice and Research}

What is being done now? To reduce the frequency of engine core icing events, pilots are instructed to avoid areas of high radar reflectivity that indicates heavy rain, even when the rain is at altitudes well below their flight path. However, this approach has had no noticeable effect in reducing the frequency of events. The reason for this is unknown. It may well be that the difference between conditions that are hazardous and those that are not, is not discernable to the pilot.

The research being supported by the ICC is focused to meet the immediate needs of the companies participating. Moreover, it is proprietary and is not available to any government agency or any company outside the consortium. Research is also being conducted by individual companies, but it also focused to their immediate needs and the results, again, are proprietary.

The National Research Council of Canada has been studying the effects of ice crystals on engines for some time. However, only recently has the importance of such research been identified and NRC's research in the area been re-emphasized as a result. NRC has capabilities in several areas: fundamental ice crystal aerothermodynamics tests, small engine altitude tests (about $3000 \mathrm{lb}$ thrust), and engine groundlevel tests over a range of thrusts. NRC has also recently, in collaboration with NASA, been developing new instruments that are needed to help characterize HIWC environments. The HIWC environments have been shown to be especially harsh to conventional cloud measuring instruments. 


\section{Technical Plan}

What is new? The NASA AEST project plans to invest in several key areas of engine core icing research. These are research areas in which NASA has unique capabilities, experience, and expertise. The research areas are:

1. Flight characterization of the HIWC environment, including instrument development in collaboration with NRC-Canada and Environment Canada.

2. Classical research in the areas of altitude testing for mid-size engines, altitude testing for engine components, development of engine ice-crystal test methods, development of ice-crystal detection methods, and, in collaboration with NRC-Canada, fundamental studies of ice particle aerothermodynamics.

3. Computational research in the areas of engine performance simulation, ice accretion simulation, and engine control methods.

Each of these areas will be discussed in further detail below.

What are the payoffs? First and foremost, a dramatic reduction in the frequency of engine core icing events will be realized by the aviation industry if the NASA AEST research is successful. Even though NASA does not have control over the implementation of the results of the engine core icing research conducted through the AEST project, this must remain the goal of NASA's AvSP and the goal of the industry with which NASA must remain intimately involved.

Also, methods for testing engines for ice-crystal icing susceptibility will be developed. Computational simulation tools will be developed and made available to both the industry and the FAA such that engine susceptibility to ice-crystal icing may be better and more confidently assessed. Finally, methods to detect engine core icing will be made available as well as methods to affect engine control so as to avoid engine core icing.

How will this research be implemented? To address the problem of engine core icing, NASA AEST first constructed a needs-based roadmap to outline the research needed to address the aviation hazard of engine core icing. The needs based roadmap helped focus the technical planning activity on what is actually needed to address the problem as opposed to adopting or incorporating solution paths that may or may not be pertinent to the challenge. The needs-based roadmap started with three basic questions:

1. How can ice accrete inside an engine?

2. How does it affect the engine?

3. How can it be prevented or mitigated?

Each of these questions spawned a subset of questions for which research topics were identified that would provide answers. The needs-based roadmap provided an overarching basis for the research. No attempt was made to assign particular tasks or to prioritize the elements. This type of roadmap identifies the research components required for the task and, more importantly, provides the framework for determining critical elements as well as the primary goals.

The entire needs-based roadmap was too large to include in this paper. However, as an example of its construction, a branch of this roadmap is shown in Figure 1. It was developed from left to right; beginning with the most basic questions that needed to be answered to address the problem. Unknowns about the conditions in the environment as well as in the engine that must be investigated are listed on the right along with specific research disciplines that must be applied to this problem.

Subsequent to the needs-based roadmap creation, a solutions-based roadmap was generated which identified key aspects of the research and showed how research elements would be addressed. It also was too large to include in its entirety in this paper. However, solutions-based roadmaps for each of the three main elements of the technical challenge are shown in Figures 2 to 4. Key steps in each area of research 
were identified along with corresponding key decision points. Decision points are critical to maintaining proper balance among the research elements and to keep the effort on track toward meeting the subproject goals. This is of particular importance when resources are insufficient to investigate every aspect of each element.

Interactions among the research elements were also identified. These are shown in the overall solutions-based roadmap (which is available from the authors). The roadmap highlighted the iterative nature of the research process and, more importantly, showed the motivations for the research as well as the goals in terms of specific outputs and outcomes.

\section{Research Areas}

\section{Flight Characterization}

The objective of this research is to characterize natural HIWC environments in terms of water content, ice crystal size, air temperature, altitude, and horizontal extent. The database will be used for several important purposes:

- To provide realistic conditions for engine icing simulation in test facilities. Without realistic targets and bounds for ice-crystal conditions in test facilities, the engine ice-crystal icing phenomenon might be misrepresented, resulting in invalid science and engineering models.

- To provide realistic conditions for engine icing simulation in computational tools. Similar to the case for test facilities, the absence of realistic targets and bounds for computational tools would likely result in invalid tool capabilities.

- To provide a sound basis for an engine HIWC icing certification envelope. Without a firm basis for design criteria, engine ice protection methods might be critically under-designed or, conversely, grossly overdesigned, resulting in unnecessary inefficiencies.

High ice-crystal content data are available in the literature, but are suspect for a number of reasons. A myriad of problems exist with the use of the available cloud measurement instruments employed to collect those data. Furthermore, the flight campaigns during which the data were collected were not typically designed to investigate HIWC conditions; thereby leaving the data statistically underrepresented. Therefore, a concerted effort to collect HIWC data from a statistically representative and accuracy standpoint is warranted.

To accomplish this, a statistical database must be established through HIWC cloud measurements made in flight. NASA, along with its partners, intends to conduct a flight campaign using a speciallyinstrumented research aircraft to characterize natural HIWC environments. NASA has a historical role in this research as it conducted key flight campaigns to characterize first the natural icing cloud environment and, more recently, the supercooled large droplet cloud environment (a type of icing cloud that has specific characteristics which differentiate it from typical icing clouds).

The flight campaign is to be conducted in two phases. First, a trial campaign will be conducted to check out the aircraft, the instruments, and the data acquisition capabilities. The second campaign will be to collect the data needed to establish the database.

As part of this flight research, new instruments are being developed and existing instruments are being adapted to withstand the particularly harsh HIWC conditions. The ice crystals present in HIWC conditions have been known to literally erode instruments away to the point of inoperability, similar to sandblasting. Also, they have generated the buildup of static electricity in or on instruments to the point of rendering them inoperable. Furthermore, ice-crystal bounce can make them much more likely to become artificially concentrated over that which exists naturally. Care must be taken to position the instruments on the aircraft to avoid bounce concentration as well as design of the instrument must sometimes be altered to avoid inadvertent deflection of crystals into the sampling stream. Finally, unlike liquid droplets, which are typically spherical, ice crystals can be of irregular shapes, making them difficult to size 
properly. NASA has partnered with both NRC-Canada and Environment Canada in order to develop instruments to adequately measure HIWC conditions.

Finally, the data collected during the flight campaign must be analyzed. Because of the number of instruments required and the time-consuming nature of the analysis of the data collected and its significance, time will be needed to adequately ensure its accuracy and report the data.

\section{Classical Research}

Classical research refers to theoretical analysis, test facility and method development, and experimental investigations of and for engine core icing research. It includes fundamental research of ice particle aero-thermodynamics, phase change, impact, accretion, and shedding. The fundamental research necessarily includes the theoretical analysis needed for model development which is used to form a basis of understanding for the phenomenon as well as for use in computation tools. Testing and test method development include a range of experimental research from that performed in static rigs to help understand fundamental physics of the process, to that in rotating rigs to help understand the physics at the component level, to full engine testing to ensure the models apply at the engine system level.

NASA AEST, however, does not have sufficient resources to conduct all of this research. Therefore, in collaboration with its partners and the engine icing community, NASA AEST has selected the following key research focus areas to pursue. Each area will be described in further detail below.

- Fundamental ice particle physics and scaling studies in collaboration with research partner, NRC-Canada

- Engine ice-particle test facility development in the form of an engine icing capability at NASA GRC’s Propulsion Systems Laboratory

- Engine HIWC altitude effects research

The creation of theoretical models, the establishment and development of test facilities and methods, and the testing of both fundamental physics as well as engine component and system tests will form the backbone of a viable research and development program designed to address the safety hazard of engine icing.

Costs of experimental research are high and resources are scarce. Therefore, the research conducted here will have clear test objectives defined to meet specific research needs as outlined in the needs based roadmap and confirmed by the other research areas in the project. Tests will be conducted as prescribed in the solutions roadmap and results will be assessed, again, in terms of the research needs. Each individual aspect of the research will be pursued only until the research needs are met, or until other research areas are deemed more important, at which point the particular level of technology development will be declared.

\section{Fundamental Ice Particle Physics and Scaling Studies}

\section{Fundamental ice particle physics studies}

These studies involve experiments designed to test hypotheses modeling engine core icing processes including impact, phase change, accretion, erosion, etc. The experiments will be conducted in small wind tunnels using static geometric shapes conducive to fundamental studies but also representative of components found in jet engines. Early experiments intend to determine the envelope bounding the conditions for the onset of ice accretion through ice shedding by testing over a range of conditions. The conditions include ice water content (IWC), liquid water content (LWC), ambient temperature, surface temperature, and pressure. Later experiments will focus on more detailed understanding of both first and second order effects. 
The purpose of the these Fundamental Ice Particle Studies is to further understand the mechanisms of ice accretion on surfaces exposed to ice crystal and mixed-phase conditions similar to those encountered during engine power-loss events. The studies will ultimately form the basis upon which computational engine ice accretion simulation tools as well as engine design and analysis tools can be built.

This research will also advance measurement techniques which are specifically needed for ice-crystal testing. Since ice shapes rapidly melt after tests in warm environmental conditions expected for icecrystal testing, traditional methods of measuring ice shapes such as ice tracings are not practical. Therefore, techniques are needed to make quantitative ice shape measurements without physically accessing the test article either during or shortly after testing. Imaging techniques are to be explored ranging from simple high-resolution imagery to 3D stereo imaging. Other techniques may be considered depending on the success of the imaging techniques. Finally, surface measurements of key parameters such as water and ice-film thickness and droplet and ice-crystal impacts are to be made as these elements are important to understanding the basic mechanistic elements of how ice-crystals accrete inside the core of an engine.

This research task will be a joint effort between NASA and the National Research Council of Canada (NRCC) whose relationship is documented via a Letter of International Agreement. The NRCC is making available their Research Altitude Test Facility (RATFac) for the experimental studies. The Federal Aviation Administration also provides support for research at the RATFac.

\section{Fundamental ice particle scaling studies}

This research is closely related to, and integrated with, the studies described in a) Fundamental ice particle physics. The main objective of this research is two-fold. First, it's to assess the feasibility of using a simple airfoil to duplicate the "ice crystal accretion" phenomenon in conditions identified in the above physics studies. In particular, the possible altitude effect on ice crystal accretion will be examined. It will identify the essential scaling parameters that govern the ice crystal accretion process. Secondly, it will develop and evaluate appropriate scaling methods for ice crystal accretion on simple blade geometry for environment conditions (first priority) and size (second priority).

From ice particle physics studies, an envelope bounding favorable conditions for ice particle accretion will be determined for simple blade geometry and a non-intrusive imaging measurement technique will be available for obtaining full-span 3D ice shape profiles. Also, a validation database will be available for the evaluation and possible modification of numerical codes and analytical models for ice crystal accretion simulation based upon the current working hypothesis. However, due to limited resources, this type of parametric-study database/knowledgebase acquisition will not have sufficient coverage of the relevant icing regimes. To better achieve ice-particle physics research objectives, a scaling study (i.e., dimensional analysis) of ice particle accretion on simple engine blade geometry will be undertaken. Because icing scaling studies often push the limits of testing facility capabilities, the result is to produce an even broader range of icing conditions in the facility. Consequently this scaling study will support the development of ground-based experimental simulation test capabilities such as the NASA GRC Propulsion Systems Laboratory (PSL) icing test cell.

\section{Engine Ice-Particle Test Facility Development}

An engine core icing test capability has been designed and is being incorporated into NASA GRC's PSL. NASA's AEST project, as a major customer for this capability, will provide support, in the form of research expertise and procurement funding, to check out, calibrate, develop (if needed), and validate this capability.

Existing engine core icing test facilities consist primarily of outdoor, ground-based facilities that are limit to the ambient air temperatures and pressures of the geographic region where they are located. Very few engine core icing test facilities exist that have altitude capability, but they have other limitations such as very low thrust capacity. The engine core icing community, including both industry and government agencies, have unanimously called for PSL icing capability. 
The incorporation of an ice-particle generation system in an engine test facility is a complex task. It has never been attempted before in an engine test facility as complex or sophisticated as PSL. Moreover, icing cloud simulation facilities have always proven to be challenging to calibrate in terms of particle size, concentration, and special distribution. New techniques will need to be developed to accomplish these tasks in PSL. Finally, NASA management has determined that to be shown viable, an engine core icing validation test will need to be conducted in PSL to validate its icing capability.

\section{Engine HIWC Altitude Effects Research}

This element of the Engine Icing Technical Challenge is designed to address the role altitude plays in engine core icing. It will build upon several concurrent research elements of the Engine Icing Technical Challenge to first derive a model of how ice accretes inside an engine core, form a hypothesis of the effects of altitude on the icing process, and then test the hypothesis in an engine test conducted in PSL where the effects of altitude can be simulated.

Engine core-icing events are occurring over a range of aircraft from business jets to large commercial transports. Atmospheric conditions typically consist of clouds formed from high convective activity such as those associated with tropical rainstorms. Because of the high level of convective activity, the events occur over a large range of altitudes from 10,000 to over $39,000 \mathrm{ft}$.

Tests have shown that, under certain circumstances, ice is accreting on engine surfaces at temperatures well above freezing. It is likely and, in fact, broadly accepted among engine experts that complex heat and mass transfer phenomena are occurring to allow ice to exist and accrete inside an engine core at these above-freezing temperatures. Because heat and mass transfer are dependent upon pressure of the working fluids, it is likely that altitude plays an important role in the ice accretion. However, due to facility limitations, altitude affects have not yet been investigated.

The concurrent research elements involved in this study include:

- Computational engine performance simulation

- Computational engine icing simulation

- Ice-particle physics studies

- Engine icing scaling studies

\section{Computational Research}

Computational research for engine core icing refers to the application of modern numerical simulation codes to the investigation, understanding, and ultimately, the solutions to this aviation safety hazard. The research includes the development and application of numerical codes in three major categories. Each of these will be described further below.

- Engine performance simulation - the adaptation and application of existing engine performance codes to predict the effects of core icing on engine performance

- Engine ice accretion simulation - the adaption and application of principles and techniques developed for supercooled liquid droplet airframe icing to predict engine core icing

- Engine control simulation - the application of integrated propulsion control techniques to help prevent engine core icing

Over the course of the past two decades, great strides have been made in the development of engine performance simulation codes, ice accretion simulation codes, and automated engine control and control simulation capabilities. The development and application of these capabilities for the purpose of addressing the hazard of engine core icing will provide insight and guidance to the Classical Research 
activities which form the backbone of the research required to effectively address the problem of aircraft icing. NASA alone has the unique combination of capabilities and expertise to carry out the integration of these distinct, but closely coupled tasks in this research element.

A description of the how these codes will be developed and applied to the technical challenge is given in the solutions-based roadmap. Key decision points are built into the processes to assess code validity, verify the application, and determine if further model development and/or higher fidelity simulation is required to meet the technical challenge of engine icing.

\section{Engine Performance Simulation}

NASA AEST seeks to further develop a system of computer codes based on legacy NASA engine simulation codes that were designed to predict engine operation and performance. The codes include both full engine system simulation and engine component simulation codes. Levels of simulation fidelity range from 0D engine thermodynamic system codes to 1D (mean line) and 2D (streamline curvature) component flow analysis codes. Longer range research using 3D computational fluid dynamics (CFD) codes may be eventually needed. The 1D and 2D codes will be adapted and applied first, with higher level (3D CFD) codes being subsequently employed as needs require. Several specific tasks have been identified for this research:

- Acquire an engine system input file for Numerical Propulsion System Simulation (NPSS) (Ref. 7) and a detailed description of the compression system geometry and flow conditions, specifically the fan and low pressure compressor (LPC) from an engine that has experienced icing due to ice crystal ingestion at altitude, with sufficient detail to perform a mean-line flow analysis. Additional data required are all parameters and logic necessary to control the engine throughout the flight envelope. The development of engine performance simulation tools for engine core icing requires that an extensive set of relevant engine and flight data information be made available to the code developers. The intent is to have validated and verified computer simulation tools that can be applied to assess icing susceptibility in the fan and low pressure compressor and its effect on engine performance and operability. To this end it is critical to acquire engine system performance and geometric details of a compressor from an engine that has experienced icing due to ice crystal ingestion at altitude.

- Conduct a parametric study of the effect of blockage due to ice buildup (accretion) on engine system performance. The engine system code and the 1D (mean line) compressor flow analysis code (Refs. 8 and 9) will be tightly coupled such that they exchange boundary conditions at each iteration at each operating point until convergence. This is a departure from the traditional methodology, which is to utilize compressor characteristic maps to define the LPC performance. The reason this is necessary is twofold. First, as the blockage due to ice buildup increases, the compressor characteristic performance changes from the baseline, that is, the efficiency, pressure ratio, surge margin and choke margin change due to the additional blockage. Second, there is a need to understand the blade-row by blade-row flow conditions within each low pressure compressor stage which quite often is a multi-stage compressor. The traditional technique using overall performance maps does not have the fidelity to provide this. In the new methodology, the engine system code and the mean line compressor flow analysis code are executed simultaneously, thus, the compressor flow code effectively takes the place of the performance maps. By this technique, the compressor analysis code provides the overall pressure ratio and efficiency directly to the engine system model in real time at every operating condition, eliminating the need for compressor maps. In addition, the compressor code provides the detailed flow field within the multiple blade rows of each of the LPC stages. Compressor performance with ice accretion will be estimated by parametrically varying the blockage in a mean line compressor flow analysis code at each engine operating condition. Each level of blockage due to ice accretion will result in a new estimate by the mean line code of the compressor performance 
in the engine system environment. The effect of varying amounts of ice accretion is thus conveyed to the engine system model in real time at each operating condition in the flight trajectory. The engine performance model will be calibrated with flight data obtained during known icing events to determine the degree of blockage due to ice accretion. This assumes availability to NASA of engine geometry and performance data for a representative engine that has experienced icing events due to ice crystal ingestion at altitude.

- Conduct a study of the effect of computed blockage due to ice buildup within the low pressure compressor on engine system performance. A detailed description of the flow conditions within the low pressure compressor along its operating line through the flight envelope will be generated with the system code coupled to the mean line compressor code. Initially, this data will be provided to the ice accretion model. The Icing Branch (RTI) will execute the ice accretion model throughout the complete flight envelope to determine the altitude and location in the compressor where ice can be expected to accrete on the compressor stator vanes or walls. The ice accretion analysis results will be used to calibrate the engine system-compressor analysis code. At a later phase in the project, the ice accretion code will be coupled to the engine system code and the compressor flow analysis code. Thus, the full capability of the three codes, once fully coupled, will be to detect where in the compressor ice accretion may occur, and apply the appropriate level of blockage to the compressor analysis code. The level of blockage is a function of time at a particular operating point along the flight trajectory. The compressor analysis code then is run to determine the effect of the additional blockage on the compressor performance. The "modified" compressor performance is then passes to the engine system code to determine the effects on the engine power balance. These analyses with the three codes mentioned take place simultaneously, such that each code is run with the appropriate boundary conditions for a given point along the engine/aircraft flight trajectory. The engine performance model with the effects of computed ice accretion blockage will be reconciled with flight, or simulated altitude test data obtained during known icing events.

- Build upon the previous study on the effect of computed blockage due to ice accretion within the low pressure compressor on engine system performance. The methodology of this phase will be identical to the previous one, with the exception that here a two-dimensional (2D) empirical based Euler turbomachinery (through-flow) code will be utilized, in place of the 1D mean line compressor flow analysis code. These details will be provided to the ice accretion model. The engine system code, the 2D compressor analysis code, and the ice accretion model will be executed simultaneously throughout the complete flight trajectory to determine the altitude and location within the compressor where ice can be expected to accrete. Compressor performance will be calculated with the through-flow compressor analysis code utilizing the additional blockage computed by the ice accretion code. The expected outcome of these analyses is to determine the degree of ice accretion along the compressor flow path walls and its distribution on the stator vanes. Blockages due to ice accretion will result in a degradation of the compressor performance. The engine performance model with the effects of computed ice accretion blockage will be reconciled with flight data obtained during known icing events or with test data from an engine exposed to ice crystal icing conditions in a test facility. A higher fidelity version of the ice accretion model will be investigated, which would have the capability to model the flow through the fan and low pressure compressor in a quasi-three dimensional manner. This will enable simulating the actual compressor geometry and provide improved realism to the analysis for effects such as flow incidence at the stator leading edges. 


\section{Engine Ice Accretion Simulation}

NASA AEST seeks to develop engine core icing codes that will predict the accretion of ice inside an engine when conditions are conducive to such an event. The research seeks to determine the environment conditions under which the icing can occur, the location inside the engine where it will occur, the rate at which ice accretes, and how much ice will accrete. The research will require close collaboration with the engine performance simulation effort in that accurate prediction of the engine environment as well as the effects of the ice on the engine performance will be critical to the ice accretion prediction.

This research will provide an invaluable tool to both engine designers who seek to create new, highly efficient engines as well as engine certification authorities who seek to ensure the safe operation of these new engines. Moreover, the results of this research will be directly applicable and provide critical support to help guide the activities of the Classical Research element of this sub-project.

Two important phases of the engine ice accretion simulation element have been identified:

1. Develop an ice accretion simulation tool to calculate mixed phase ice accretion on engine duct walls and isolated stator blades using strip theory, the Messinger model, and a 1D transient, conjugate heat transfer model along the surface. The tool will interface with 3D, steady state, average-passage type flow solutions to determine the mixed phase state through the engine. Strip theory will be used to determine convection heat transfer and runback paths for the duct and blade surfaces. A 1D, transient, conjugate heat transfer module will be used to determine the ice shapes along the duct and blade surfaces.

2. Develop ice accretion simulation tool to calculate mixed phase ice accretion on engine components. The tool will interface with 3D, steady state, average-passage type flow solutions to determine the mixed phase state through the engine. Heat transfer and runback paths will be determined from the Navier-Stokes based flow using fully 3D methods. The Messinger model, and a 1D transient, conjugate heat transfer model will be used to determine ice shapes on the engine components.

The engine icing simulation tool development will require the generation of experimental databases for model development and validation. These experimental tests will be supported under the Classical Research project element.

\section{Engine Control Simulation}

The NASA AEST seeks to develop automatic engine control methods that either mitigate the effects of engine core icing or prevent it altogether. The automatic engine control would be altered such that the effects of icing on engine performance would be taken into account by the automated control or the control methods would be applied so that conditions conducive to core icing would not be permitted inside the engine. Engine operation would be shifted to a different point inside its operating envelope. Whether detection of ice crystals in the engine airstream is necessary or not for effective execution will need to be determined.

The ultimate goal of reducing engine core icing events is dependent not only upon discovering how it occurs and how it affects engine operation, but also upon finding effective means to prevent core icing from occurring. Under NASA's Integrated Resilient Aircraft Control project, a sophisticated engine simulation and control methodology (CMAPPS40k) was developed, validated and verified. The AEST project, in collaboration with NASA's Vehicle Systems Safety Technologies (VSST) project, seeks to capitalize on this technology by applying it to the technical challenge of engine icing. 


\section{Summary}

A description of NASA's overall technical plan for investigating the problem of jet engine core icing due to flight in high ice-crystal content cloud environments is given in this paper. These accumulations of ice have resulted in numerous unexpected engine events including rollback, surge/stall, flameout, and component damage. The development of research roadmaps designed to address the problem in a robust manner is described. These roadmaps form the framework for the subproject, showing both how the separate elements compliment and support each other as well as show how the support achieving the goal of eliminating engine malfunctions and damage due to ice-crystal icing.

Descriptions of the technology elements are also given so as to provide an understanding of the state of the art in each area and to help understand the technological gaps that exist to address the problem of ice-crystal engine icing.

\section{References}

1. “Technical Compendium From Meetings of the Engine Harmonization Working Group,” FAA Report No. DOT/FAA/AR-09/13, March 2009.

2. “Task 2 Working Group Report on Supercooled Large Droplet Rulemaking,” Prepared by: Ice Protection Harmonization Working Group (IPHWG), With Recommendations From: Flight Test Harmonization Working Group (FTHWG), Powerplant Installation Harmonization Working Group (PPIHWG), Engine Harmonization Working Group (EHWG), December 2005.

3. “Mixed-Phase/Glaciated Icing Technology Plan,” EHWG Technology Plan Document—Version 1.1 Dec. 20, 2005.

4. “Aircraft Loss of Control Study—Final Report,” NASA Internal Report, February 2010.

5. "Systems Analysis of NASA Aviation Safety Program-Final Report,” Jones, Sharon Monica, Langley Research Center, Hampton, Virginia, Reveley, Mary S. and Withrow, Colleen, Glenn Research Center, Cleveland, Ohio, Evans, Joni K., ATK, Space Division, Hampton, Virginia, Barr, Lawrence C., Volpe National Transportation Systems Center, Cambridge, Massachusetts, Leone, Karen, ASRC, Inc., Cleveland, Ohio, June 2010.

6. "Causal Factors and Adverse Conditions of Aviation Accident and Incidents Related to Integrated Resilient Aircraft Control,” Reveley, Mary S., Briggs, Jeffrey L., and Sandifer, Carl E., Glenn Research Center, Cleveland, Ohio, Evans, Joni K., ATK, Space Division, Hampton, Virginia, Jones, Sharon M., Langley Research Center, Hampton, Virginia, NASA/TM-2010-216261, Nov 2010.

7. Jones, S.M., “An Introduction to Thermodynamic Performance Analysis of Aircraft Gas Turbine Engine Cycles Using the Numerical Propulsion System Simulation Code,” NASA/TM-2007214690.

8. “Axial and Centrifugal Compressor Mean Line Flow Analysis Method,” Veres, Joseph P., AIAA-2009-1641, NASA/TM-2009-215585.

9. “Conceptual Design of Compressor for Two Spool LCTR-2 Engine,” Veres, Joseph P., Thurman, D., NASA/TM-2011-216264. 


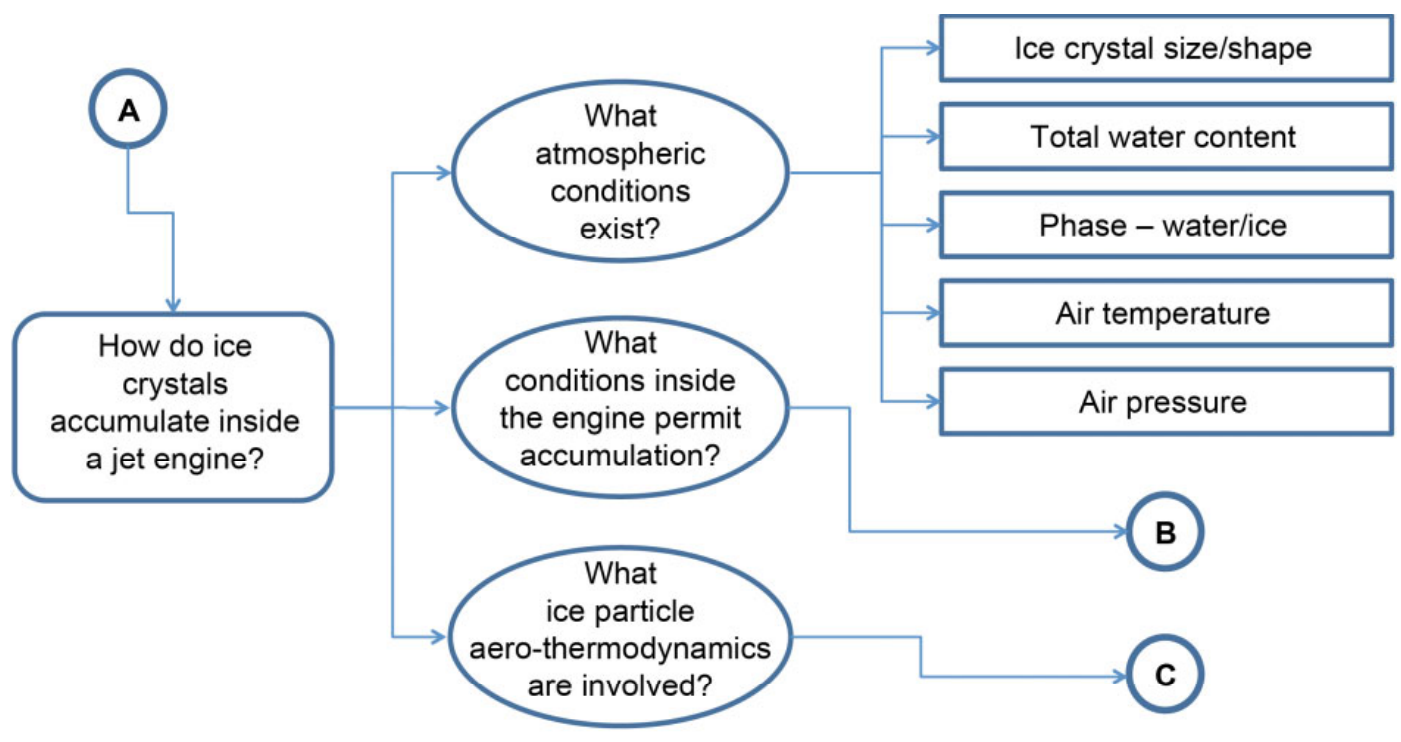

Figure 1.-Example branch from the Needs-based roadmap used to develop the NASA Engine Icing Technical Plan. (A) depicts the connection to the overall High Ice-Crystal Content Research area and to the other two main questions that need to be answered to address the problem. (B) and (C) indicate branches of research similar to the one above them on the roadmap.



Figure 2.-Solutions-based roadmap for developing new measurement instrument capabilities. (A) indicates the link to the atmospheric environment which is conducive to engine core icing. (B) shows the link to classical research in the form of existing test capabilities in Figure 3. 


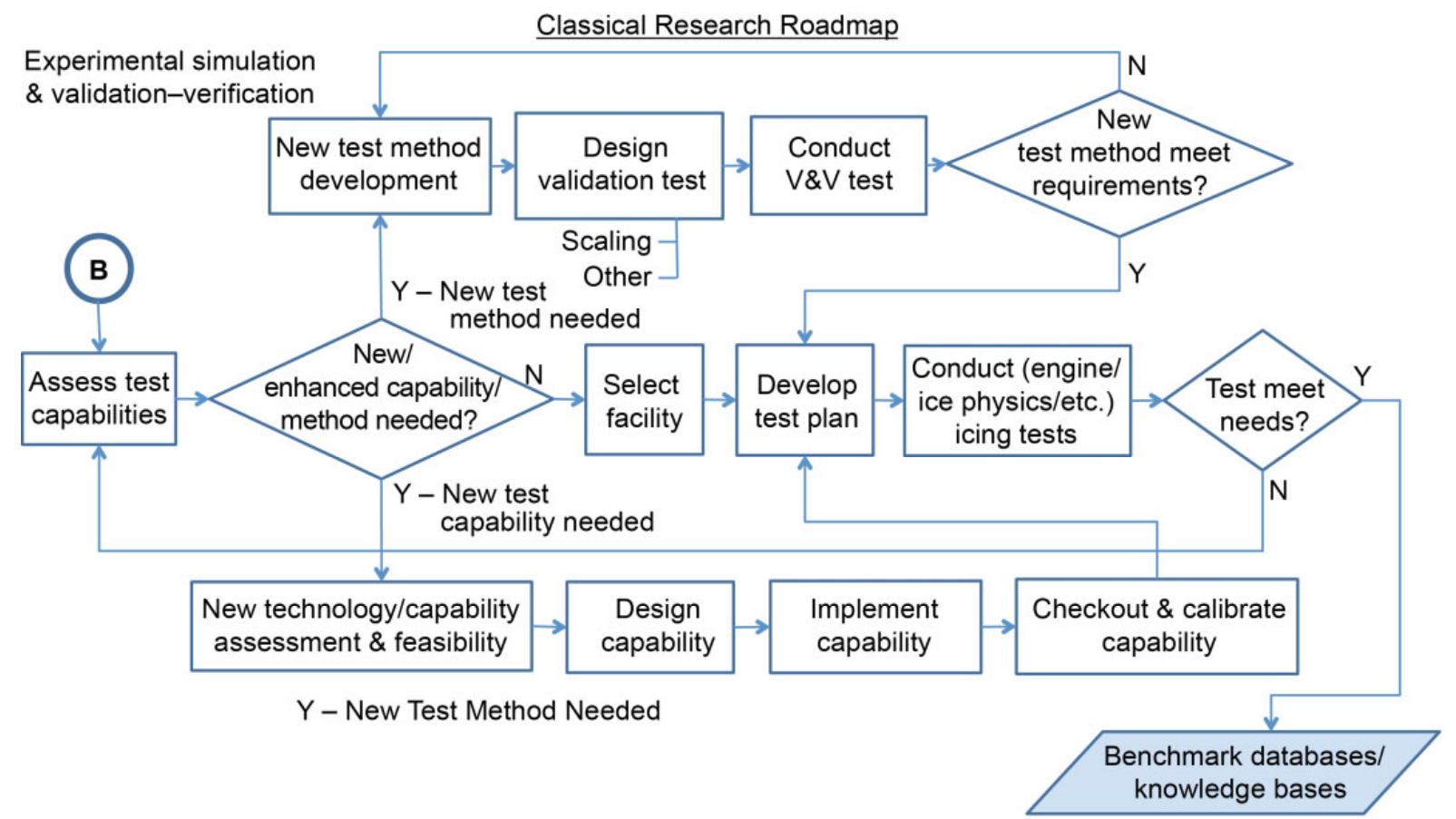

Figure 3.-Solutions-based roadmap for ice-crystal engine icing classical research. (B) shows the link to measurement capabilities in Figure 2 required for engine core icing studies.

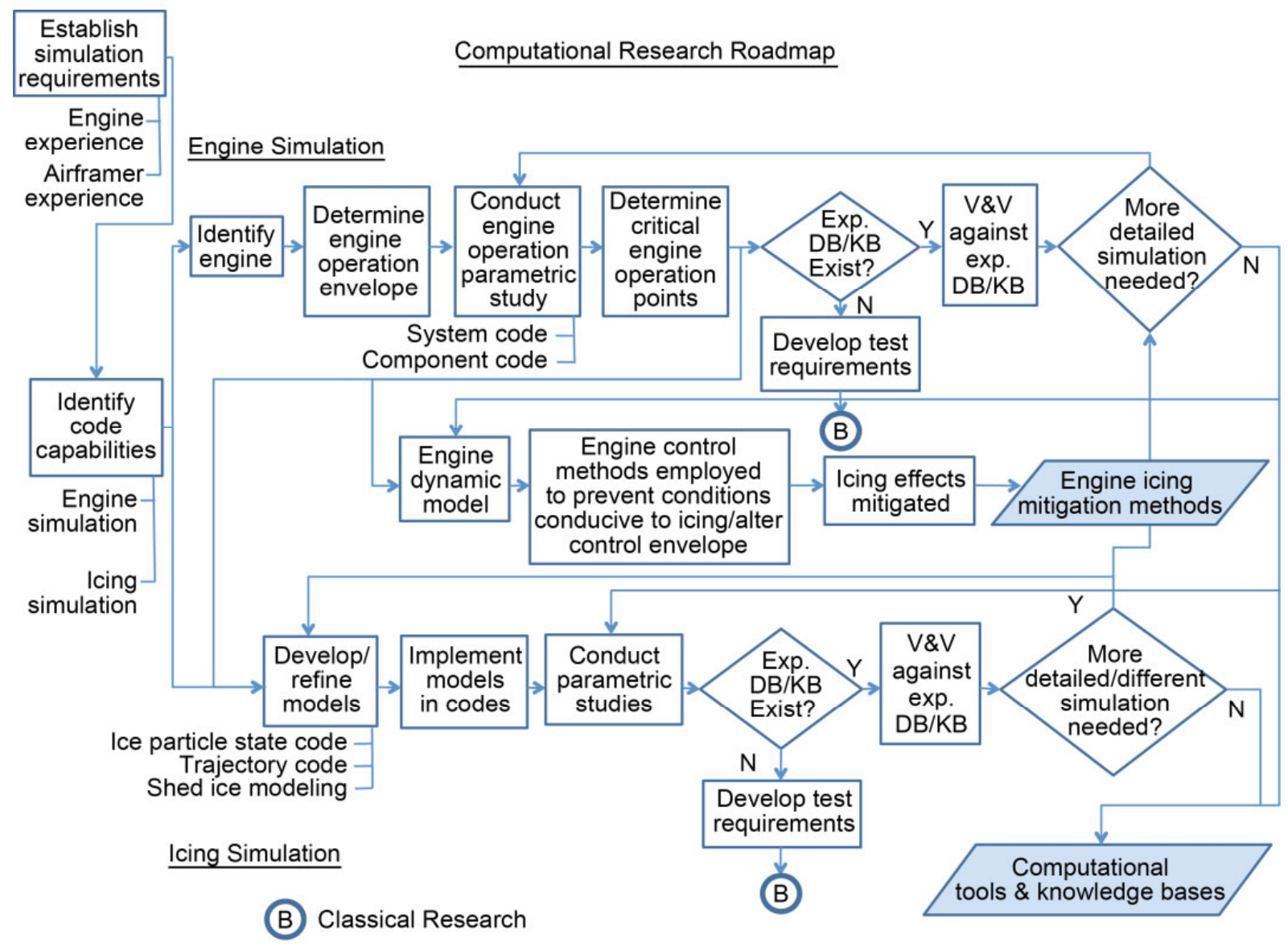

Figure 4.-Solutions-based roadmap for ice-crystal engine icing computational research. 


\begin{tabular}{|c|c|c|}
\hline \multicolumn{2}{|c|}{ REPORT DOCUMENTATION PAGE } & $\begin{array}{l}\text { Form Approved } \\
\text { OMB No. 0704-0188 }\end{array}$ \\
\hline \multicolumn{3}{|c|}{$\begin{array}{l}\text { The public reporting burden for this collection of information is estimated to average } 1 \text { hour per response, including the time for reviewing instructions, searching existing data sources, gathering and maintaining the } \\
\text { data needed, and completing and reviewing the collection of information. Send comments regarding this burden estimate or any other aspect of this collection of information, including suggestions for reducing this } \\
\text { burden, to Department of Defense, Washington Headquarters Services, Directorate for Information Operations and Reports (0704-018), } 1215 \text { Jefferson Davis Highway, Sulite } 1204 \text {, Arlington, VA } 22202-4302 \text {. } \\
\text { Respondents should be aware that notwithstanding any other provision of law, no person shall be subject to any penalty for failing to comply with a collection of information if it does not display a currently valid OMB } \\
\text { control number. } \\
\text { PLEASE DO NOT RETURN YOUR FORM TO THE ABOVE ADDRESS. }\end{array}$} \\
\hline $\begin{array}{l}\text { 1. REPORT DATE (DD-MM-YYYY) } \\
01-11-2011\end{array}$ & $\begin{array}{l}\text { 2. REPORT TYPE } \\
\text { Technical Memorandum }\end{array}$ & 3. DATES COVERED (From - To) \\
\hline \multirow{3}{*}{\multicolumn{2}{|c|}{$\begin{array}{l}\text { 4. TITLE AND SUBTITLE } \\
\text { An Overview of NASA Engine Ice-Crystal Icing Research }\end{array}$}} & 5a. CONTRACT NUMBER \\
\hline & & 5b. GRANT NUMBER \\
\hline & & 5c. PROGRAM ELEMENT NUMBER \\
\hline \multirow{3}{*}{\multicolumn{2}{|c|}{$\begin{array}{l}\text { 6. AUTHOR(S) } \\
\text { Addy, Harold, E., Jr.; Veres, Joseph, P. }\end{array}$}} & 5d. PROJECT NUMBER \\
\hline & & 5e. TASK NUMBER \\
\hline & & $\begin{array}{l}\text { 5f. WORK UNIT NUMBER } \\
\text { WBS 648987.02.02.03.10 }\end{array}$ \\
\hline \multicolumn{2}{|c|}{$\begin{array}{l}\text { 7. PERFORMING ORGANIZATION NAME(S) AND ADDRESS(ES) } \\
\text { National Aeronautics and Space Administration } \\
\text { John H. Glenn Research Center at Lewis Field } \\
\text { Cleveland, Ohio 44135-3191 }\end{array}$} & $\begin{array}{l}\text { 8. PERFORMING ORGANIZATION } \\
\text { REPORT NUMBER } \\
\text { E-18009 }\end{array}$ \\
\hline \multirow{2}{*}{\multicolumn{2}{|c|}{$\begin{array}{l}\text { 9. SPONSORING/MONITORING AGENCY NAME(S) AND ADDRESS(ES) } \\
\text { National Aeronautics and Space Administration } \\
\text { Washington, DC 20546-0001 }\end{array}$}} & $\begin{array}{l}\text { 10. SPONSORING/MONITOR'S } \\
\text { ACRONYM(S) } \\
\text { NASA }\end{array}$ \\
\hline & & $\begin{array}{l}\text { 11. SPONSORING/MONITORING } \\
\text { REPORT NUMBER } \\
\text { NASA/TM-2011-217254 }\end{array}$ \\
\hline \multicolumn{3}{|c|}{$\begin{array}{l}\text { 12. DISTRIBUTION/AVAILABILITY STATEMENT } \\
\text { Unclassified-Unlimited } \\
\text { Subject Category: } 01 \\
\text { Available electronically at http://www.sti.nasa.gov } \\
\text { This publication is available from the NASA Center for AeroSpace Information, 443-757-5802 }\end{array}$} \\
\hline
\end{tabular}

\section{SUPPLEMENTARY NOTES}

\section{ABSTRACT}

Ice accretions that have formed inside gas turbine engines as a result of flight in clouds of high concentrations of ice crystals in the atmosphere have recently been identified as an aviation safety hazard. NASA's Aviation Safety Program (AvSP) has made plans to conduct research in this area to address the hazard. This paper gives an overview of NASA's engine ice-crystal icing research project plans. Included are the rationale, approach, and details of various aspects of NASA's research.

15. SUBJECT TERMS

Aircraft icing; Jet propulsion; Computerized simulation; Atmospheric moisture; Atmospheric physics

\begin{tabular}{|l|l|l|l|l|l|}
\hline \multicolumn{2}{|l|}{ 16. SECURITY CLASSIFICATION OF: } & $\begin{array}{l}\text { 17. LIMITATION OF } \\
\text { ABSTRACT }\end{array}$ & $\begin{array}{l}\text { 18. NUMBER } \\
\text { OF } \\
\text { PAGES }\end{array}$ & $\begin{array}{l}\text { 19a. NAME OF RESPONSIBLE PERSON } \\
\text { STI Help Desk (email:help@sti.nasa.gov) }\end{array}$ \\
\cline { 1 - 1 } $\begin{array}{l}\text { a. REPORT } \\
\text { U }\end{array}$ & $\begin{array}{l}\text { b. ABSTRACT } \\
\text { U }\end{array}$ & $\begin{array}{l}\text { C. THIS } \\
\text { PAGE } \\
\text { U }\end{array}$ & UU & 19 & $\begin{array}{l}\text { 19b. TELEPHONE NUMBER (include area code) } \\
\text { 44-757-5802 }\end{array}$ \\
\hline
\end{tabular}



